\title{
Çeyiz Sandığını, Giyilebilir Sanat İle Anlatmak: Sandık Sarısı Koleksiyonu
}

\author{
DOI: $10.26466 /$ opus.728845
}

*

\author{
Beyhan Pamuk* \\ * Dr.Öğr.Üyesi Uşak Üniversitesi Güzel Sanatlar Fakültesi Uşak/Türkiye \\ E-Posta: beyhan.pamuk@usak.edu.tr O ORCID: 0000-0002-1725-3851
}

\section{Öz}

Toplumun örf, adet, gelenek, görenek gibi yaşam biçimini şekillendiren değerler, toplumun sanat-kültür yapılanmasının da temelinde yer almaktadır. Sanat ve kültürün kesişme noktalarından biri olan ancak günümüz şartlarında kaybolmaya yüz tutmuş "Çeyiz Sandı̆̆g" geleneğinde hem sanatsal hem de kültürel değerler yer almaktadır. Dünyanın pek çok bölgesinde aynı amaç ama farkl biçimlerde hazırlanan çeyiz kültürü Anadolu topraklarının da yüzlerce yıllık bir geleneğidir. Özellikle kadınların el emeği ile hazırladıkları ve duygularının dışa vurum biçimi olan ancak unutulmuş kültür değerlerinden çeyiz sandıklarında, kadınlara ait eşsiz güzellikte ve güzel olduğu kadar da yaşanmışlık dolu el sanatları ürünleri görülmektedir.Motif, desen, dokuma, işleme çeşitlerinin yer aldığ t tekstil ürünlerinden oluşan çeyiz, sanatın bir dal olan giyilebilir sanat ile bütünleştirilebilen malzemelerdir. Çünkü giyilebilir sanat kavramı sanatçıların/tasarımcıların bir ifade aracı olarak tekstil ürünü olan giysiden yararlanmaları ile gelişmiştir. Dokuma sanatı içerisinde kendini gösteren giyilebilir sanat anlayışı ile sanatçılar, yeni formlar, farklı bakış açıları ile eserlerini yorumlarken kültürel değerlere de vurgu yapmışlardır. Kültürel değerlerimizi yaşatmak, farkındalık oluşturmak, tanıtmak amacıyla sanatın evrenselliğinden yararlanılan bu çalışmada; kültürel bir değere sahip olan, halen bir neslin vazgeçemediği, kadına dair yaşanmışlıkları temsil eden "Çeyiz ve Çeyiz Sandığı" olgusunu sanatın bir açısı olan "Giyilebilir Sanat" anlayışı üzerinden yorumlanmaktadır. Çalışmada, 7 kadına ait çeyizden 63 parça tekstil ürünü kullanılarak "Sandık Sarısı Koleksiyonu " hazırlanmıştır. Koleksiyonun hazırlanma aşamasında kullanılan parçaların manevi değerleri göz önüne alınarak parçalara zarar verilmeden birleştirme teknikleri kullanılmıştır. Böylelikle parçalar istenildiği takdirde orijinal hallerine dönüştürülebilecektir. Hazırlanan bu koleksiyon ile günümüzün hem kültürel hem de tasarımsal sürdürülebilir anlayışına vurgu yapılması amaçlanmıștır.

Anahtar Kelimeler: Çeyiz, Giyilebilir Sanat, Kültür 


\title{
Explaining Drawer Chest with Wearable Art Collection of Yellow Dower-Chest
}

\begin{abstract}
Values that shape the life style of society such as customs, traditions and customs are also at the basis of the art-culture structure of the society. In the tradition of "Dowry Chest", which is one of the intersection points of art and culture, but has disappeared in today's conditions, both artistic and cultural values are included. The dowry culture, prepared in the same purpose but in different ways in many regions of the world, is a centuries-old tradition of Anatolian lands. Especially in the dowry chests, which are prepared by women by hand and which are the expressions of their feelings, but forgotten cultural values, there are unique and beautiful handicraft products as well as liveliness belonging to women. The dowry consisting of textile products including motif, pattern, weaving and embroidery are materials that can be integrated with wearable art, which is a branch of art. Because the concept of wearable art has been developed with the use of clothing, textile products as a means of expression by artists / designers. With the wearable art concept that shows itself in the weaving art, the artists emphasized cultural values while interpreting their works with new forms and different perspectives.In this study, in which the universality of art is utilized in order to keep our cultural values alive, to raise awareness and to promote them; The phenomenon of "Dowry and Dower-Chest", which has a cultural value, which still cannot be given up by a generation, and represents the experiences of women, is interpreted through the "Wearable Art". concept, which is an aspect of art. In the study, "Yellow of the Chest Collection" was prepared by using 63 pieces of textile products from dowry of 7 women. Considering the moral values of the pieces used in the preparation of the collection, combining techniques were used without damaging the pieces. Thus, parts can be converted to their original form if desired. With this collection, it is aimed to emphasize today's sustainable understanding of both cultural and design..
\end{abstract}

Keywords: Dowry, Wearable art, Culture 


\section{Giriş}

Evlenme töreni, kadın ve erkeğin sosyalleşme sürecinin önemli bir aşamasını oluştururken, gerek aileler arasında kurulan dayanışmayı, gerekse toplumsal ve ekonomik ilişkiyi belirlemesi ve düzenlemesi bakımından her zaman ve her yerde önemli bir olay olarak ele alınmıştır. Ailenin, toplumsal yapının temeli olması, bu birliği sağlayan evlenme olayına evrensel bir karakter kazandırmıştır. Geçmiş ve günümüzde dünyanın her yerinde her aşaması, bağlı bulunduğu kültür yapısının öngördüğü belirli kurallara ve kalıplara uydurularak gerçekleştirilen evlenme olayı, özellikle tören, töre, adet, gelenek ve görenek bakımından zengin bir tablo çizmektedir (Örnek, 2000; Özkan, 2012,s.20)

Çeyiz, dünyanın pek çok yerinde tarih boyunca kadınların evlenme şansını artıran bir araç olarak görülmüş, çoğunlukla büyük ailelerin gücünü ve zenginliğini artırmada, hatta zaman zaman ülke sınırlarının ve devlet politikalarının belirlenmesinde etkili olmuştur. Geleneksel yapıdaki birçok toplumda, düğün sürecinde erkeğin yaptığı hazırlığa karşılık gelinin ailesinin bir jesti olarak görülmüştür. Bu değiş tokuş, taşıdığı ekonomik nitelik dışında evliliğin onanması anlamına gelir ve iki aile arasındaki dostluğun sağlamlaştrrılmasında etkili olmuştur (Çavuşoğlu,2013,s.27).

Çeyiz hazırlama kültürünün temel yapısını; aile olma yolunda karar alan kadın ve erkeği hayata hazırlamak, bu süreçte aile bireylerinin katkısını ortaya koyarak birleşmenin getirdiği güçlü yapı ile toplum değerlerini korumak ve neslini yaşatmak oluşturmaktadır. Çeyiz, sosyal statülere göre somut ve soyut değerler içerisinde hazırlanmıştır. Arazi, değerli mücevherler, değeri yüksek mal ve mülklerde çeyiz kapsamında yer alırken ayrıca halı, kilim, dokuma, giysi yada yatak örtüsü, misafir takımı, mutfak örtüleri gibi günlük yaşamda kullanılması ön görülen el emeği ile hazırlanan ve büyük özen ve beceri gerektiren tekstil ürünlerin bulunduğu "çeyiz sandığı" da bu kapsamda yer almıştır.

Yüzyıllardır Asya'dan Avrupa'ya birçok kültürün içerisinde yer alan ve bölgelere göre farklı biçimleri ve isimleri olan "çeyiz sandığı" Anadolu topraklarında da vazgeçilmez varlığını sürdürmektedir. Günümüz şartlarına göre özellikle büyük şehirlerdeki kültür yozlaşmasından nasibini almış olsa da Anadolu'nun pek çok yerinde varlığını bir şekilde sürdürmektedir. Nas (2018) yapmış olduğu çalışmasında çeyiz konusunu şöyle ifade etmektedir: 
"Yillar boyunca ataerkil aile içerisinde geleneklerine bağh olarak yaşayan Anadolu kadını, açıklamakta güçlük çektiği, çekindiği, dile dökemediği bazı duygu ve düşüncelerini, kişiliklerini, istek ve arzuların el sanatlar kapsamında değerlendirilen ürünler üzerinde göstermiştir. Bu çerçevede ele alınan çeyizlerde gözlenen motiflerdeki dil zenginliği dünya görüşünün, zevkin ve yaratma gücünün somut kavramlarla ölümsüzleştiği bir duygu, düşünce ve hayal dünyası haline gelmiştir. Anadolu kadınları yüzyıllardır dilinin düğümlendiğgi zamanlarda kelimesiz bir şekilde duygularm anlatmışlardır. Söz konusu anlatımlarda doğal, çeoresel ve duygusal etmenler birer esin kaynağı olarak görsel nesnelere dönüşerek iletişim kurmanın en kısa ve en etkili yolu olmuştur"

Çeyizin geçmişteki hazırlanma sürecinde, bir koleksiyon olarak gelişim aşamasından itibaren birçok kere geçici olarak nitelenebilecek sergilerle küçük izleyici grubu ile buluşurdu. Örneğin komşular arasında henüz evlilik kararı ya da durumu olmaksızın çeyiz gezmeleri yapılırdı. Bunun yanı sıra zaman zaman sandık hem çeyizin geldiği son durumu görmek hem de çeyizde yer alan yadigârları hatırlamak üzere hane halkı tarafından açılırdı ve içindekiler tek tek serilirdi (Demir,2017,s.132). Geleneksel Türk El Sanatları üzerinde çalışan Glassie (1993),Çeyizi; “Genç kızlar, evlenmeden önce dokuma sanatların öğrenirken, gelecekte evinde kullanmak üzere güzel olan şeylerin toplandı̆̆ı bir koleksiyon meydana getirirler. Bu çeyizdir. Çeyiz ayn zamanda genç kızın ilerdeki hayatında kullanabileceği bir sermayedir" şeklinde ifade etmektedir.

Çeyiz sandıklarının içerisindeki eşyaların yanı sıra çeyiz sandığı da özel olarak hazırlanmaktadır. Genellikle ahşaptan hazırlanırken yüzey tasarımlarında ahşap oymacılığının yanı sıra gümüş, bakır işlemeleri ile de bezenmektedir. Çeyiz sandığı, içine sadece bohçalar, yazmalar, danteller konan kapalı bir kutudan çok daha fazlasıdır. Uzun bir süreçte hazırlanan ama en son tamamlanan çeyiz en güzel hayallerin, umutların ve el değmemiş bir saflı̆̆ın özenle konarak saklandığı, her evin vazgeçilmezidir. Geçmişten günümüze birçok toplum, birçok kültür kendilerini ifade etmek için en çok sanatı kullanmıştır ve bu açıdan çeyiz sandıkları da birer sanatçının elinden, o sanatçıların yaşadığı topluma, kültüre göre şekillenmiş ve özelliklerini almıştır. Her sanat eseri bir hikâye anlatır esasında ve günümüzde her ne kadar önemsenmese bile bu sandıkların da birer hikâyesi mevcuttur. (Özkan,2012,s.2)

Bu çalışmada, kaybolmaya yüz tutmuş yada günümüzün sosyal yaşantısinda değişime uğramış olan geleneksel değerlerden "çeyiz ve çeyiz sandı̆̆ı" yaşantısı giyilebilir sanat anlayışı ile yorumlanmaya çalışılmıştır. Özellikle 
geçmiş yıllarda yeni bir hayat kurmanın heyecanı ile el emeği göz nuru ile hazırlanan ve her bir parçasında duygu, düşünce, dilek, temenni, hayal, mutluluk gibi birçok duyguyu barındırarak hazırlanan çeyiz, belki de aynı amaç içerisinde var olan sanatın giyile bilirliği ile bütünleşerek sandığın dışında varlığını gözler önüne serebilecektir.

\section{Giyim, Moda ve Giyilebilir Sanat}

Beslenmeden sonra insanlık için önem taşıyan temel fizyolojik ihtiyaç "örtünme" olmuştur. Başlangıçta tamamen fonksiyonel bir amaç taşıyan örtünme daha sonra insan vücut formuna ve ergonomisine daha uygun hale gelerek giyinmeye ve süreç içinde de özellikle kapitalizmin sembolik öğelerinden biri olarak moda olgusunun da eşlik ettiği yeni bir boyuta taşınmıştır. Tarihsel süreç içinde giysiye her gün yeni bir anlam yüklenmiştir. Önceleri çevresel koşullardan korunma anlamı taşıyan giysiler daha sonra toplumsal bir statünün, bir mesleğin, siyasi bir bakış açısının ya da kişisel bir duruşun biçimsel simgesi haline gelerek, teknik boyutlarının ötesinde sosyolojinin, sosyal psikolojinin, ekonominin hatta tarihin ilgi alanı içinde önemli bir yer bulmuştur.

Giyim, zaman içerisinde bulunduğu toplumun inanç, kültür, yaşam tarzını üzerinde barındıran, diğer topluluklara görsel mesaj ileten bir araç halini almıştır. Mertebeleşmenin hakim olduğu geleneksel toplumlarda giyim; kişinin içinde bulunduğu sosyal sınıfın özelliklerini yansıtmaktadır (Barbarosoğlu,2004, s.9). Giyim, insanın kişisel duygu ve düşüncelerini yansıtma, sayginlık kazanma, bir guruba ait olma ya da kendini ispatlama yoluyla toplumsal ilişkilerini etkileyen bir faktör olarak da görülmektedir (Koca vd., 2009, s. 743).

Davis'e (1992) göre, giyim görüntüye dayanan bir iletişim aracıdır. Bir anlamda kişinin kendisini ifade etme biçimidir. Davis, kişinin mesleği, cinsiyeti, yaşla ilgili olarak belirleyici nitelikleri, mesai dışı zamanlardaki eğilimleri, yerel ve dinsel kimlikleri, politik ve ideolojik eğilimleri ve daha birçok özelliği giydiği giyside kendini hissettireceğini belirtmektedir. Sosyo-psikolojik ihtiyaçları karşılama açısından giyim, bir topluma yada bir kültüre ait olma hissi sağlar, insanların toplumdaki rollerinin bir işaretidir ve bir rolden diğerine 
geçiş yapmada yardımcı olmaktadır. Bütün bunların yanı sıra giyecekler insanların sosyal davranışlarını, değerlerini ve toplum içindeki sosyal değişmeyi de yansiturlar ( Koca vd.,2009,s.744).

Burada giysi ve moda kavramlarına değinmek yararlı olacaktır. Giysi ve moda bir birinin yerine kullanılan ancak yanlışlığı pek de yadırganmayan iki kavramdır. Giysi yukarıda da belirtilen gerekçelere dayalı olarak teknik bir süreç sonunda iki boyutlu bir tekstil yüzeyini üç boyutlu hale getirme işi iken moda bu süreç sonunda ulaşılan giysilerin gündemde kalma süresidir. Her ne kadar moda kavramı giyimle özdeşleşmişse de aslında bunun d1şında ve ötesinde hiç şüphesiz ki daha geniş bir kapsama alanına sahiptir. Sadece giyimin değil mobilyadan otomobile, pek çok objenin modasından söz edilebilir. Kısaca moda; giyim kuşamın çok ötesinde insanoğlunun hemen hemen tüm toplumsal etkinliklerini kapsayan bir olgu ve sanatla özellikle de görsel sanatlarla yakın ilişkisi bulunmaktadır.

Moda, her zaman bir sanat dalı olarak kabul görmek istemiştir. Moda tasarımcıları, dönemin sanat akımlarından etkilenmiş veya dönemin farklı alanlardaki sanatçıları ile yollarını kesiştirerek insan bedenini sanat sergileme alanı olarak kullanmıştır. Giysinin insan bedeninde taşınması ve sergilenebilir olması birçok alana ait yeniliğin yaşamın içine sokulmasında giyilebilir hale getirilmesine neden olurken, yeni bir kavram olarak giyilebilirlik kavramı bu kapsamda kullanılmaya başlanmıştır. Ama moda, yine de farklı dönemde ve birçok sanatçı tarafından modanın misyonu ve yapısı gereği sanat olarak kabul edilmemiştir.

19.yy sonlarına doğru ortaya çlkan Haute Couture anlayışı ile giysiler bir sanat eseri olarak sunulmuş, dönemin modaciları Frederick Worth ve Paul Poiret tarafından yenilikçi düşünce, sanatsal giyim veya giyilebilir sanatı moda dünyası ile buluşturulmuştur. Ancak modanın "Giyilebilir Sanat" teriminin ilk olarak 1960'ların sonları 1970'lerin başında New York ve San Francisco' da ortaya çıktığı bilinmektedir (Günay, 2014, s.53). Giyilebilir sanat düşüncesiyle sanatçlar kendi kısıtlı çevreleri için giysi formları tasarlama amacıyla yola koyulmuşlardır. 20.yy sanatının gelişen kavramsal alt yapısı moda olanı değil de giysinin sanat olmasına ortam hazırlamıştır. Lif sanatı çerçevesinde yavaş yavaş oluşmaya başlayan giyilebilir sanat anlayışı henüz adı konmamışken bile sanatçıların eserlerini üretirken yeni form ve kavram, özgün teknik materyal arayışlarında yer almıştır. Giyilebilir sanat anlayışına dayanarak kumaş dokuma teknikleri, baskı tasarımları, dikiş ve nakış çözümleri 
ile kurgulamaları ile heykelimsi giysiler yapmışlardır. Modanın doğasını en iyi anlatan obje olan giysinin maddesel karakterden çıartılıp kavramsal bir karaktere bürünmesi ve bedenle olan ilişkisinin daha açık bir şekilde anlamlandırılması giyilebilir sanat kavramı ile mümkün olmaktadır. Giyilebilir sanat, moda endüstrisinin toplum üzerindeki yaptırım gücüne ve olumsuzlukları ile savaşmak adına geliştirilen bir sanat yorumu olarak adlandırılmıştır. Tasarımların doğuş amacı ve üretilme yöntemleri açısından son derece farklı olan giyilebilir sanat icra eden sanatçılar eserlerinin farkını ortaya koymak adına orijinal ve vizyoner bir bakış açısıyla yeni doku ve yüzey arayışlarıyla tasarım gücü yüksek eserler kurgulamaktadır (Atik,2019,s.39-42).

Günay (2014) konu ile ilgili çalışmasında şunları ifade etmektedir.

" Giyilebilir sanat, sanatm ve tasarmmm içiçe geçebildiği günümüzde, ele alınan bakış açılarına göre farkh yorumlarla tanımlanabilmektedir. Moda tasarımcısı olup bunu sanatsal bir çerçeveye oturtanlar kavramsal sanat ya da heykelsi hacimler vasttasi ile sanat nesnesi yaratıyorlar. Kullanılan renkler ve biçimlerin bir tuval üstündeki renk ve biçimler gibi değer görmesi, aynı sanatsal endişeler ile yaratıldıkları düşünülürse şaşırtıcı olmayacaktır. Bunun yanı sıra sanatçı kimliği ile sanat nesnelerini yaratırken giysi formunu kullanan ya da onun yüzeyini bir tuval gibi tasarlayan sanatçlar da bulunmaktadır. Giyilebilir sanat içerisinde kavramsal sanata yakın duranlar, sanattaki bir işe yaramak için var olmayan ve fakat sanat nesnesi olarak var olan nesneye kendilerini daha yakm hissediyor ve ona göre kendilerini konumlandirnyorlar. Yaratılan nesnelere giyilebilir sanat deniyor; çünkü bir giysi formunu andırma durumu var; ancak fonksiyonellik özelliği giysinin geleneksel anlamından uzaklaşıldı̆̆ ölçüde yok oluyor ve giysi bir ressamın tuvali ya da bir heykeltıraşın çamuru gibi bir konum elde ediyor. Başka bir deyişle, yaratılan nesne sanat yapma dürtüsü ile yaratillyor ve giysi kelimesinin siradan basit tanımından farkl bir anlam kazanarak sanatçının onu başka bir boyuta taşımast ile sanat nesnesi haline geliyor".

Sanatçıların eserlerini yaratırken bir ifade aracı olarak tekstil ürünü olan giysiden yararlanmaları giyilebilir sanat kavramını geliştirmiştir. Giyilebilir sanat ifadesi sonucunda ortaya çıkan tasarımların sanatsal nitelikleri tasarımcılarına sanatçı sıfatını uygun görmekte olduğu söylenilebilir. Bugün dünyada isim olmuş moda tasarımcları sanatçı olarak kabul görmektedirler ve kumaşlar onların tuvalidir. (Atik,2019,s.42; Aktepe 2012,s.55)

Sonuç olarak, sanat-tasarım kimliği içerisinde oluşan kişilik, eserini tasarlarken hissettiği duyguları ve vermek istediği mesaj ya da düşünceyi giysi 
formuna yansıtmaktadır. Dokuyarak, işleyerek, dikerek veya elindeki malzemeyi yeniden işleyerek esere kendi dokunuşunu yaparak yeniden yorumlamaktadır.

\section{"Sandık Sarısı" Koleksiyonun Hikâyesi}

Modernleşmenin getirileri günlük yaşantıda değişimleri de beraberinde getirmektedir. Bu değişimler geniş aile olmanın bütünleştirici etkisini azaltmakta ve "çekirdek aile " tanımının da altında bireyselleşmeyi oluşturmaktadır. Daha hızlı olma, en pratik yaşam şeklini kurgulama, dijitalleşme, geniş ürün yelpazeleri ve satın almada kolaylıklar vb. sayılabilecek birçok faktör kültürel miraslardan pek çoğunda olduğu gibi "çeyiz sandığı" kültürünü de günümüz coğrafyasında kültürel nesnelerin yerini sorgulatır hale getirmiştir.

"Çeyiz Sandığ1" hala bir neslin vazgeçemediği kültürel bir değerdir. Bu mirasın yüklendiği anlam ve duygulara vurgu yapmak, gelecek nesilleri haberdar etmek adına bu çalışmada yaşları 45 ila 83 yaş arasında olan 7 kadına ait çeyiz sandığından alınan dantel , nakış, örtü, peçete vb. parçalar giyilebilir sanat anlayışı ile yorumlanarak hazırlanan koleksiyonda sunulmuştur. Sandık Sarısı koleksiyonun temel amacı yüzlerce yıllık adetler ve inançlarla beslenen kültür, bilgi, inanç, sanat, duygu, örf ve adetleri barındıran, kadına dair birçok olguyu içine alan ancak yok olmaya yüz tutmuş çeyiz kültürünü sanatın bir dalı ile gün ışığına çıkarmaktır. Koleksiyon için kullanılan parçalara herhangi bir şekilde zarar verilmemiş olup özellikleri bozulmadan özel birleştirme teknikleri kullanarak istenildiği takdirde eski kullanım biçimine getirilebilecek şekilde tasarlanmıştır. "Sandık Sarısı " adı verilen koleksiyonda ev tekstili ürünlerinden el emeği ile hazırlanan yatak takımı, salon takımı, mutfak takımı, sedir örtüleri gruplamaları içerisinden seçilmiş, orijinal isimlerine ve kullanım amaçlarına göre yapımı ve kullanımı sırasında çeyiz sahiplerinden dinlenilen hikayelerden yola çıkılarak koleksiyon hazırlanmış ve manifestosu aşağıdaki anlatımla sunulmuştur;

- "Çeyiz... Dünyanin pek çok yerinde farklı kültürlerde ve biçimlerde "gelinler" için hazırlanan ancak hazırlanırken genç kızların, kadınların özenle duyguların, hayallerini, hayata ve sanata bakış açlarım el emeği ile yansitan kültürel bir miras... 
- Çeyiz sandığ ise çeyizi koruyan ve saklayan, onu geleceğe taşıyan, nesne olmanın ötesinde kişisel aitliği olan, hatırası, yaşanmışlığı ya da yaşamılacakları barındıran bir baş eserdir. Çeyiz, onu içinde barındıran sandık ile nesnel güzelliği kadar, temsil ettiğgi saygın aile ve evlilik değerleri ile öznellik taşır.

- Modern yaşam döngüsü içerisinde çeyiz algısı değişse de geçmişte yapılan ve hala bir neslin sandiklarında özenle saklanan çeyizleri gün yüzüne çkarmak, onları değerlendirirken, yeni nesillere aktarmak kültür ve sanat için önemli değil midir?

- Her kadinin evinde veya yakın çevresinde bulunan, her ne kadar kullanilmasa da duygusal nedenlerle elden çıkartılamayan çeyizleri, mekânlardan bedenlere taşıyarak yine-yeniden tasarlamak ....heyecan verici"

"Sandık Sarısı" koleksiyonunu 63 parça çeyiz ürünü ile Beyhan Pamuk tarafından hazırlanmıştır. Her bir parça hikayelendirilmiş ve isimleri, parçaların ve kullanım durumları ile özdeştirilmiştir.

"Nazende " çalışması yeni gelin için hazırlanan yatak takımı parçalarından oluşmaktadır. İki parçadan oluşup eski dönem yataklarda, yatağın iki tarafından sarkıtılarak yatak ve yatak odasına estetik görünüm kazandırılmaktadır. Nazende çalışması için yatak örtüsü bedene yerleştirilirken aynı takımın yastık parçası bedende omuz üzerine yerleştirilirken sevmek, nazlanmak, hoş görmek, anlamak gibi duygulara vurgu yapılmıştır. Birleştirme tekniklerinde elde dikiş yapılmış parçalara zarar verilmemiştir (Fotoğraf 1).

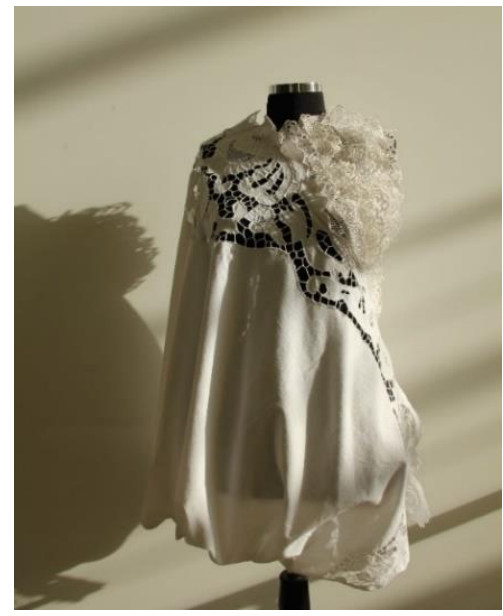

Fotoğraf 1. "Nazende" 2017 

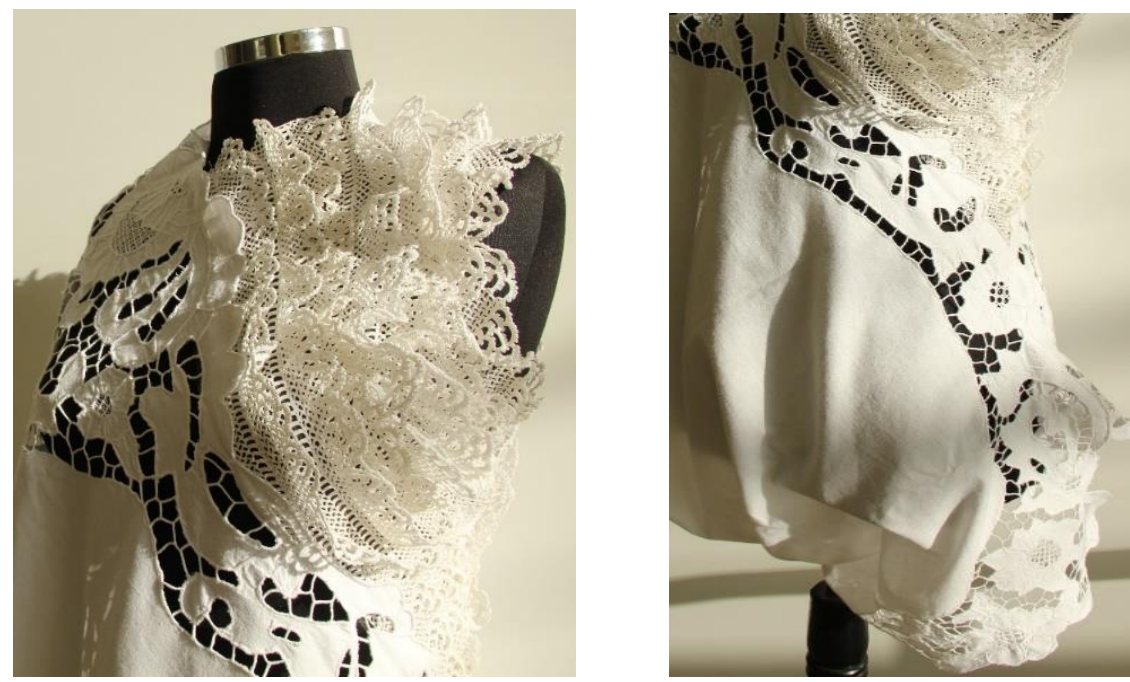

Fotoğraf 2-3. "Nazende" Detay Görselleri

Yakın geçmişe kadar Anadolu kültüründe birçok bölgede yeni evlenen çiftler erkeğin ailesi birlikte yaşamaktaydı. Bu nedenle tecrübe ve bilgi sahibi olan evin en büyük kadını (kayınvalide, büyük anne) ev içi günlük yaşamında söz sahibi olan kişiydi. Otoriter, aile yaşantısına yön veren bu kadınlardan esinlenerek "Büyük Hanım" isimli çalışma hazırlanmıştır. Anadolu'da eski dönem oturma odalarında "sedir" yaygın olarak kullanılan oturma gurubudur. Bu sedirler için hazırlanan örtüler ayrı bir önem taşımaktadır. "Büyük Hanım " isimli çalışmada evin vazgeçilmezi olan sedir örtüsü kullanılmıştır (Fotoğraf 4-5). Parça katlama teknikleri kullanılarak elde özel birleştirme teknikleri kullanılmıştır. 

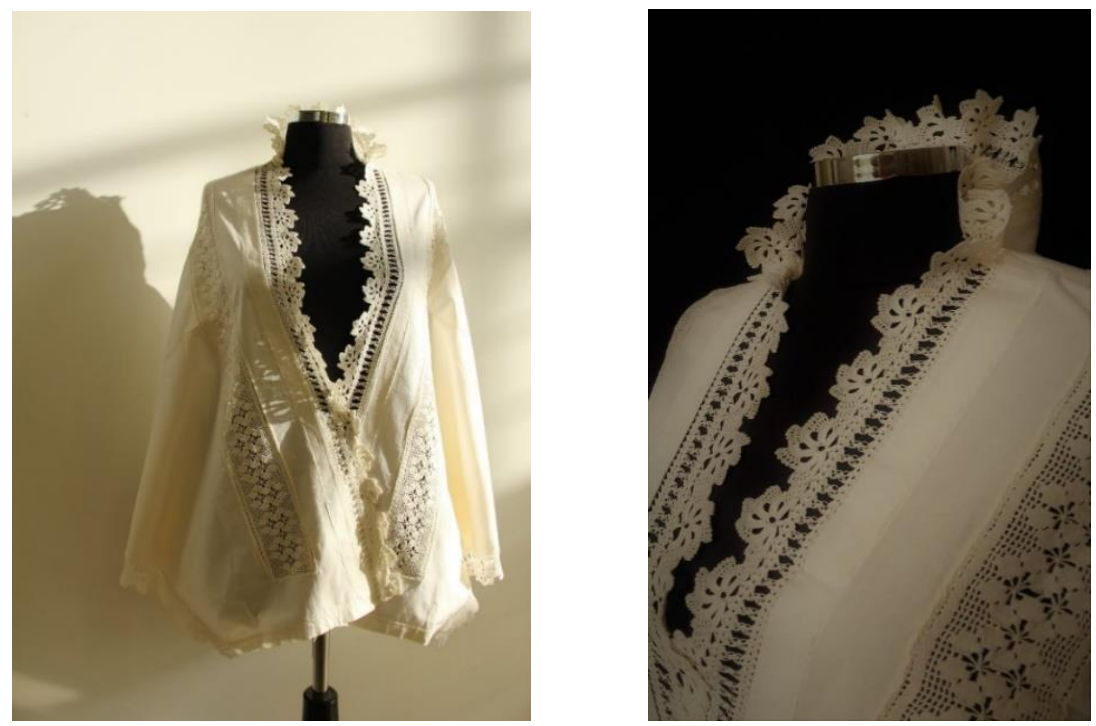

Fotoğraf 4-5: "Büyük Hanım"2017

"Sandık Sarısı Koleksiyonuna ait diğer parçalar aşağıda yer almaktadır.

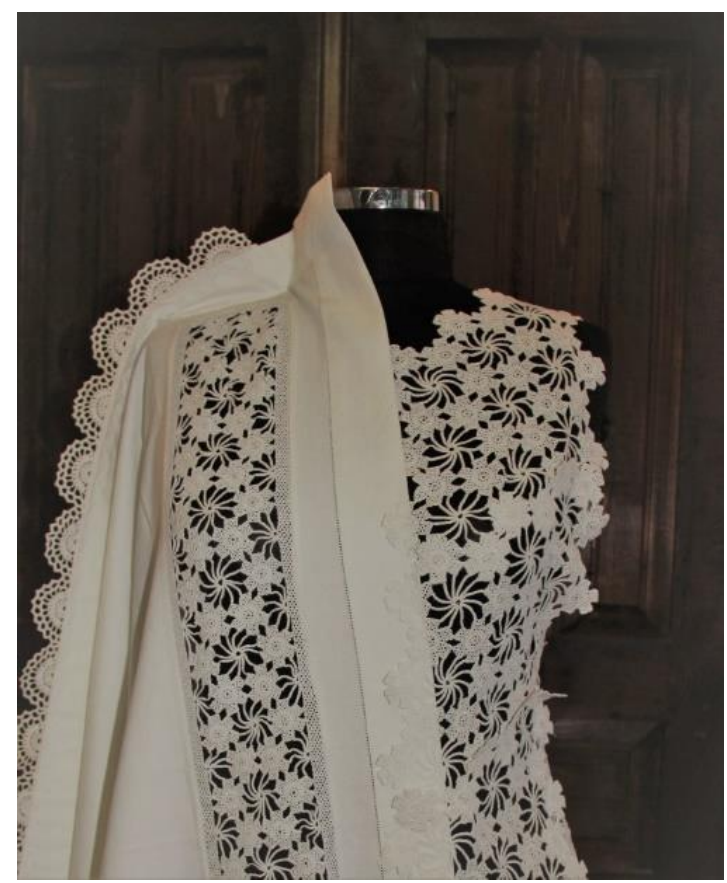

Fotoğraf 6. “Çarkıfelek" Detay 2017 


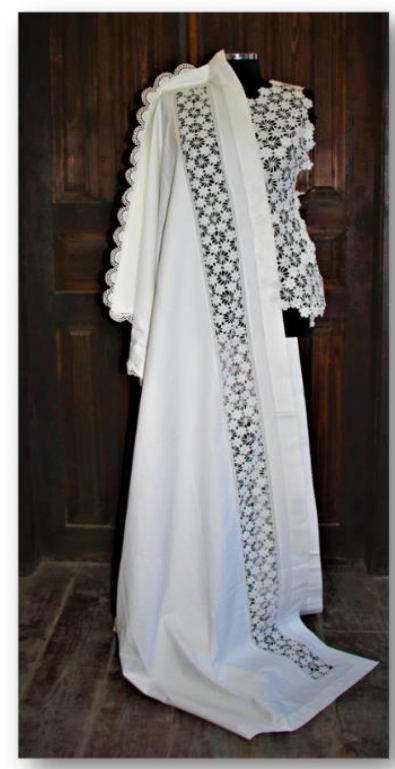

Fotoğraf 7. “Çarkıfelek" 2017

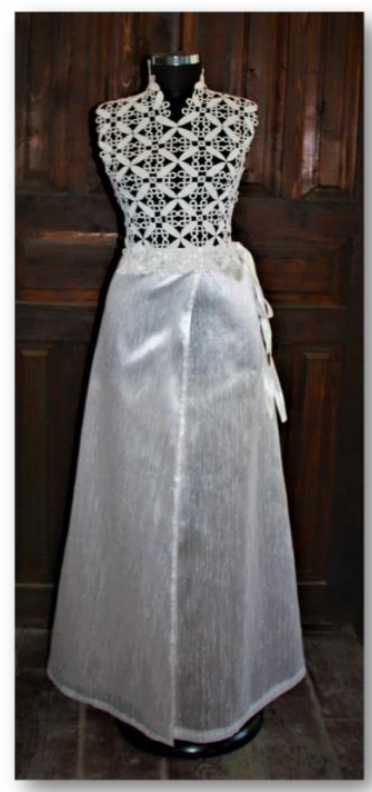

Fotoğraf 9. "Berkemal" 2017

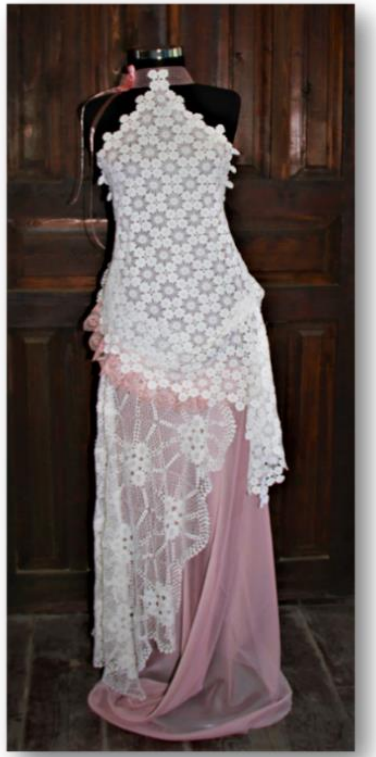

Fotoğraf 8. "Fiskos" 2017

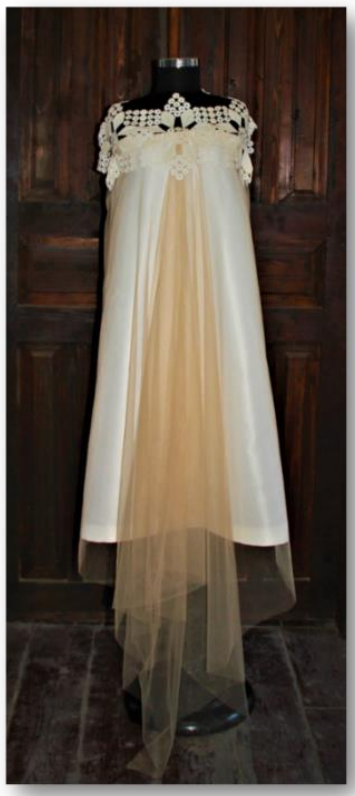

Fotoğraf 10. "Yıldız" 2017 


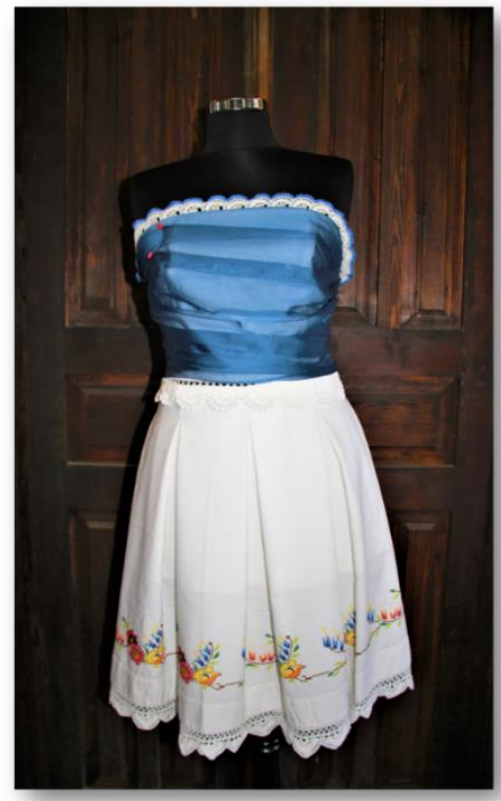

Fotoğraf 11.“Bahar Dalı" 2017

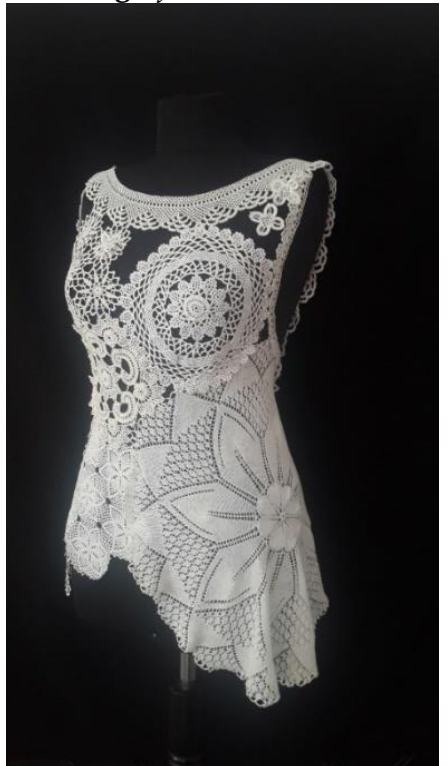

Fotoğraf 13. "Dantel Dantel" 2016

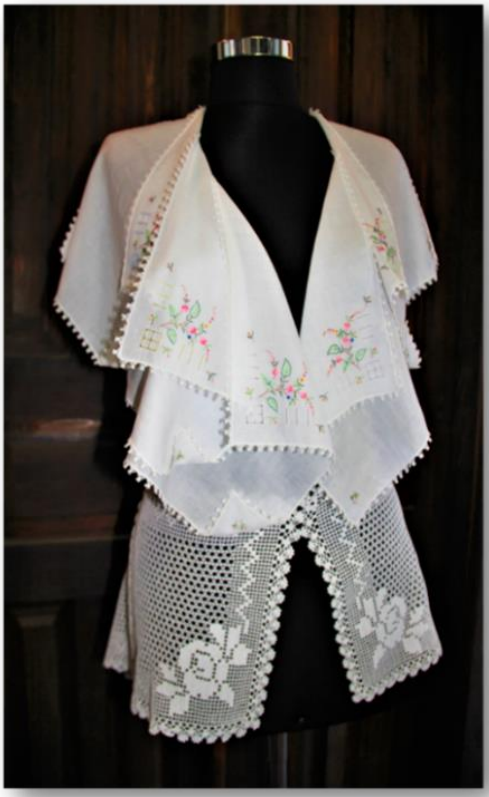

Fotoğraf 12. "Hamarat" 2017

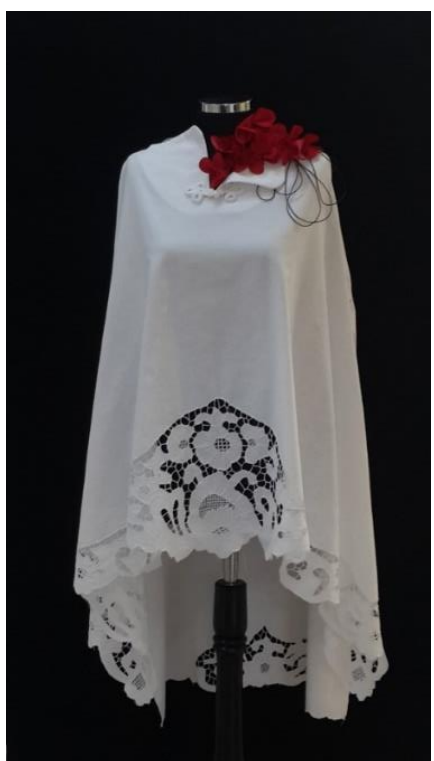

Fotoğraf 14. "Çeyiz" 2016 


\section{Sonuç}

Giyilebilir sanat yorumları ilhamını doğadan, gelenekten, kültürden, tarihten ya da giyim unsurlarından alabilmektedir. Lif sanatı olarak başlayan giyilebilir sanat örnekleri; takı, el dokumaları, işlemeler ve otantik giysiler şeklinde hayat bulurken geliştikçe bireyin stilini, ideolojisini, vizyonunu ve yaşam biçimini ifade eden görüntülere bürünmüştür. Giyilebilir sanatın ilk örneklerine bakıldığında etnik desen ve geleneklerin esin kaynağı olduğu özgün el yapımı tekstillerden oluştuğu görülmektedir. Giyilebilir sanatın ana teması olan bedenin, duyguları ifade etme alanı olarak kullanılması, insan için olanın anlatılmasını ifade etmekte güçlü bir etkiye sahip olduğu bilinen bir gerçektir. Bu gerçekten yola çıkılarak "Sandık Sarısı" koleksiyonu hazırlanmıştir.

Sandık Sarısı koleksiyonu ile yüzlerce yıllık adetler ve inançlarla beslenen kültür, bilgi, inanç, sanat, duygu, örf ve adetleri barındıran, kadın ve kadın olmaya dair birçok yaşanmışlı̆̆ içine alan ancak yok olmaya yüz tutmuş çeyiz kültürünü sanatın başka bir açısı ile yorumlanmaya çalışılmıştır. Çünkü el emeği ile hazırlanan ve kullanılan motif, desen, işleme ile bütünleştirilen duyguların dile geldiği el sanatları ürünlerini, bedende yeniden tutundurmak ve hatırlatmaktır.

Bu çalışmada yaşları 45 ila 83 yaş arasında olan 7 kadına ait 63 parça tekstil çeyiz ürünleri kullanılmıştır. Çeyizler kendileri tarafından hazırlanırken yakın çevreleri tarafından da katkı sağladığını belirten bu kadınların her bir parça için ayrı ayrı hikâyeleri bulunmaktadır. Her birisi gençlik hayalleri, gelinlik yılları, kadınlık sorumluluklarını aktardıkları bu birikimlerini günümüz yaşam şartları nedeniyle çeyiz sandıklarında halen özenle saklamaktadırlar. Koleksiyon hazırlama sürecinde bu değerleri göz önüne alınarak çeyiz parçalarına zarar verilmeden farklı birleştirme teknikleri kullanılmış ve parçalar ayrıldığında eski formunu alabilecek şekilde tasarlanmıştır. Bu kadınlara ait çeyiz sandığından alınan dantel, nakış, örtü, peçete vb. parçalar giyilebilir sanat anlayışı ile yorumlanarak hazırlanan koleksiyonda sunulmuştur. Koleksiyon Uşak Üniversitesi'ne ait Uşak Tarihi Konaklarda konsepte uygun olarak sergilenmiş ve ziyaretçilere açılmıştır. 


\title{
EXTENDED ABSTRACT
}

\section{Explaining Drawer Chest with Wearable Art Collection of Yellow Dower-Chest}

\author{
Beyhan Pamuk \\ Uşak University
}

Basic structure of dowry preparation culture; Preparing men and women who decide to become a family to life, bringing the contribution of family members in this process, preserving the values of the society and keeping them alive with the strong structure brought by the union. Dowry is prepared in concrete and abstract values according to social status. Land, precious jewelery, high value goods and properties are included in the dowry. In addition, the "dowry chest", which contains textiles that are intended to be used in daily life such as carpets, rugs, textiles, clothes or bedspreads, guest sets, kitchen covers, and which require great care and skill, is included in this scope.

The dowry chest, which has been in many cultures from Asia to Europe for centuries and has different shapes and names according to regions, continues its indispensable existence in Anatolian lands. Although it has received its share from cultural degeneration especially in big cities according to today's conditions, it still continues its existence in many parts of Anatolia.

The benefits of modernization bring about changes in daily life. These changes reduce the integrating effect of being an extended family and create individualization. Being faster, fictionalizing the most practical way of life, digitalization, wide product range and convenience in purchasing, etc. Many factors that can be considered take away from cultural heritage. It has also made the dowry chest culture question the place of cultural objects in today's geography.

In this study, the "dowry and dowry chest", which is one of the traditional values that are about to disappear or changed in today's social life, is tried to be interpreted with the understanding of wearable art. Especially in the past years, with the excitement of establishing a new life, it has been prepared by hand and contains many emotions such as emotion, thought, dream, happiness in each part. Dowry will be able to reveal its existence outside the chest, 
perhaps integrating with the wearability of art that exists for the same purpose.

In the collection, lace, embroidery, veil, napkin etc. taken from the dowry chest of 7 women between the ages of 45-83 The pieces are presented in the collection prepared by interpreting them with a wearable art approach. The main purpose of the Chest Yellow (Sandık Sarısi) collection is to bring to light the dowry culture, which contains culture, knowledge, belief, art, emotion, customs and traditions fed by centuries-old customs and beliefs, which includes many facts about women, but is about to disappear, with a branch of art.

The items used for this collection have not been damaged in any way. It has been designed in a way that it can be restored to the old way of use, if desired, by using special joining techniques without spoiling its features. In the collection called "Yellow of Dower-Chest -Sandık Sarısı", the collection was prepared based on the stories that were heard from the dowry owners during the production and use according to their original names and usage purposes, and the collection was prepared from the handcrafted bedding, living room set, kitchen set, cedar cover groupings made from home textile products. presented with narration;

"Dowry... A cultural heritage that is prepared for" brides "in different cultures and styles in many parts of the world, but reflects the emotions, dreams, perspectives of women and women on life and art with hand labor while preparing ...

The chest of dowry is a masterpiece that protects and preserves the dowry, carries it to the future, has personal belonging beyond being an object, and contains memories, experiences or experiences. The dowry carries subjectivity with the respectful family and marriage values it represents as well as its objective beauty with the chest that contains it.

Although the perception of dowry has changed in the modern life cycle, isn't it important for culture and art to unearth dowry made in the past and still carefully kept in the chests of a generation, and transfer them to new generations while evaluating them?

Re-designing the dowry found in every woman's home or close environment, which, although not used, cannot be disposed of due to emotional reasons, by carrying them from the places to the bodies.... 
Collection of Yellow Dower-Chest-Sandık Sarısı was prepared by Beyhan Pamuk with 63 pieces of dowry items. Each piece is narrated and identified with its names, parts, and use cases.

"Nazende" work consists of bedding pieces prepared for the new bride. Consisting of two parts, old period beds are hung from both sides of the bed to give the bed and bedroom an aesthetic appearance. For Nazende work, the bedspread is placed on the body, while the pillow part of the same set is placed on the shoulder, on the body, emotions such as loving, coveting, tolerating and understanding are emphasized. Hand stitched parts are not damaged in joining techniques.

Until recently, in many regions of Anatolian culture, newly married couples lived together with the man's family. For this reason, the oldest woman of the house (mother-in-law, grandmother) who had experience and knowledge was the person who had a say in the daily life of the home.

Inspired by these authoritarian women who direct family life, the work titled "The Great Lady" has been prepared. "Sedir" is the sitting group commonly used in old period living rooms in Anatolia. The covers prepared for these cedars are of particular importance.

The wooden seat (sedir) cover, which is an indispensable part of the house, was used in the work named "Great Lady". Special joining techniques are used, using part folding techniques.

With the Collection of Sandik Sarıs, the dowry culture, which contains culture, knowledge, beliefs, art, emotions, customs and traditions fed by centuries-old customs and beliefs, which includes many experiences of being a woman and a woman, but is about to disappear, has been tried to be interpreted with another angle of art. Because it is to reapply and remind the handicraft products, which are prepared with hand labor and combined with the motifs, patterns and embroidery, which express the emotions.

\section{Kaynakça / References}

Aktepe, Ş. (2012). Moda ve tekstil tasarımı sürecinde sanat / sanatçı ilişkisi. Akdeniz Sanat Dergisi, 4(7), 55-58. http://dergipark.gov.tr adresinden erişilmiştir.

Atik, D., (2019). Giyilebilir sanat ifadesi ile moda. On Dokuz Mayıs Üni.Eğitim Bilimleri Enst. Güzel Sanatlar Eğitimi Anabilim Dalı Yüksek Lisans Tezi, Çanakkale Barbarosoğlu, F.,(2002). Moda ve zihniyet. İz yayıncllk, İstanbul 
Çavuşoğlu, Ç.,(2013). Diyarbakır yöresi geleneksel çeyiz sandıkları üzerine bir deneme. El Sanatlan Araştırma Yöntemleri, İzmir

Davis, F.,(1992). Fashion, culture and identity. University of Chicago Pres Chicago

Demir, S.,(2017). Sandık ve çeyiz kültürüne müzeografik (müze ışlemleri) açidan yaklaşmak. Folklor/Edebiyat Dergisi, 23(89).

Glassie, H.,(1993). Traditional Turkish art today. 227

Günay, A.,(2014). Giyside sanatsal yaklaşım. Akdeniz Sanat Dergisi, 4(7), 51-54. http://dergipark.gov.tr adresinden erişilmiştir.

Koca, E., Koç, F., Şahinoğlu, M, ve Pamuk, B.,(2009). Toplumsal statü açısından kadınun giysi tercihlerini etkileyen etmenler. 21. Yüzylln Eşiğinde Kadınlar Değişim ve Güçlenme, Uluslararası Multidisipliner Kadın Kongresi Bildiri Metni, İzmir

Nas, E. (2018). Türk çeyiz kültürü çevresinde sözsüz iletişim dili olarak gelişen milli söz hazinesi. Turkish Studies Social Sciences. 13(18), 991-1005. DOI Number: http://dx.doi.org/10.7827/TurkishStudies.12725 ISSN: 1308-2140

Örnek, S.V.,(2000).Türk halkbilimi. Ankara:Kültür Bakanllğı HAGEM Yayınları.

Özkan, D. (2012). Antalya-Gazipaşa çeyiz sandığı geleneği, El Sanatlan Araştırma Yöntemleri I, Ege Üniversitesi Edebiyat Fakültesi Sanat Tarihi Bölümü, İzmir

\section{Kaynakça Bilgisi / Citation Information}

Pamuk, B. (2020). Çeyiz sandığını, giyilebilir sanat ile anlatmak: Sandık sarısı koleksiyonu. OPUS-Uluslararası Toplum Araştırmaları Dergisi, 16(32), 5341-5358. DOI: 10.26466/opus.728845 